\title{
Nueva edición para la obra de Adolpho Lutz: una iniciativa sin precedentes
}

\author{
The Complete Works of Adolpho Lutz: \\ an unprecedented work in review
}

\author{
Sandra Caponi \\ Profesora del Departamento de Saúde Pública \\ Universidade Federal de Santa Catarina \\ Rua Esteves Júnior 605/1414 - Centro \\ 88015-130 Florianópolis - SC - Brasil \\ sandracaponi@newsite.com.br
}

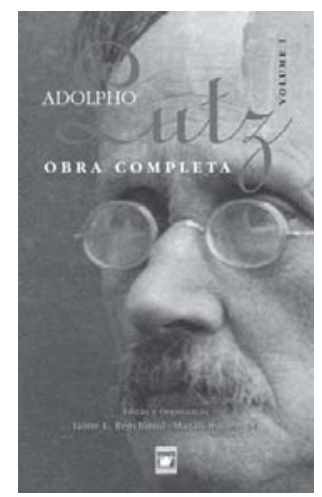

Jaime L. Benchimol \& Magali Romero Sá (org.)

Adolpho Lutz. Obra completa. (v. I: caja con cuatro libros.) Rio de Janeiro: Ed. Fiocruz, 2004.

\section{E} 117 de junio de 1953 la comisión creada para la Conmemoración del Centenario del nacimiento de Adolpho Lutz se había fijado la meta de editar un volumen conteniendo la bibliografía completa de su obra acompañada de un resumen de cada texto y se proyectaba también la reimpresión de sus trabajos más importantes. Bertha Lutz contribuyó con esfuerzos incansables para localizar los textos publicados por su padre y para organizar y clasificar ese material. Sin embargo, las conmemoraciones del centenario no tuvieron el alcance esperado y el proyecto de la edición de los trabajos de Lutz debió ser postergado.

Diez años más tarde, con ocasión de la celebración del jubileo de plata del Instituto Adolpho Lutz, Bertha intentó hacer viable, nuevamente sin éxito, el proyecto de reeditar total o parcialmente la monumental obra de Lutz, compuesta por más de 250 trabajos publicados en diversos idiomas (alemán, francés, inglés y castellano) con planchas y dibujos ilustrativos de sus estudios, junto con una extensa correspondencia que Lutz mantuvo con científicos del mundo entero. Entre los muchos caminos recorridos por Lutz en sus 61 años de trabajo hay una amplia diversidad de temas y asuntos, diferentes ramas de la medicina fueron abordadas, tales como la lepra, la micología, las enfermedades tropicales, estudios de parasitología, de entomología médica, de zoología. Esta diversidad de temas hacía aún más compleja la tarea de realizar un compendio comentado de los trabajos como deseaba Bertha.

Cincuenta años después, "el sueño de Bertha Lutz" de ver publicada la obra de su padre finalmente pudo realizarse gracias al esfuerzo de los editores Jaime Benchimol y Magali Romero Sá. Así, la tarea de edición, que fue varias veces propuesta y pospuesta, se concretiza con la publicación del primer volumen de una colección que incluye otros cinco volúmenes que serán publicados próximamente. El proyecto de edición, que exigió la reorganización del acervo principal de textos de Lutz del Museo Nacional de Río de Janeiro, y el mapeamiento de los estudios existentes en la Casa de Oswaldo Cruz y en el Instituto Adolpho Lutz, incluye además de los volúmenes mencionados, la creación de la Biblioteca Virtual Adolpho Lutz actualmente en elaboración con colaboración de Bireme (Centro Latinoamericano y del Caribe de Informaciones en Ciencias de la Salud). 
Si bien es cierto que los editores realizaron el sueño de Bertha Lutz, podríamos decir, sin temor a equivocarnos, que ellos tuvieron la osadía de superarlo. La presentación y organización de esta edición de las Obras Completas, con el auxilio de referencias de especialistas, de un suplemento conteniendo los resúmenes de los trabajos reunidos en cada volumen, índices remisivos en diferentes idiomas, un glosario de los términos técnicos citados por Lutz, traduce un extremo rigor académico que nos permite penetrar en la compleja trama de temas y problemas abordados por el científico. Cada volumen contiene entre tres y cinco libros, y cada libro está organizado temáticamente. El primer volumen reúne tres libros y un suplemento. Un libro dedicado a los primeros trabajos publicados entre los años 1878 y 1883 en Alemania, Suiza y Brasil, un segundo libro que integra las investigaciones de Lutz referidas a la hanseníasis y un tercer libro que comprende los estudios dedicados a dermatología y micología.

En cada libro, con ediciones bilingües, los trabajos están además organizados cronológicamente con prefacios de especialistas, reconocidos en el área temática, encargados de analizar la relevancia de esa producción científica. Una extensa contextualización histórica, escrita por los editores, nos permite reconstruir los diálogos, las controversias científicas, los conflictos políticos, así como los desafíos teóricos e institucionales asumidos por Adolpho Lutz en cada momento histórico preciso de su larga carrera como científico. Cada volumen está reunido en una caja impecablemente presentada, en la que cada detalle gráfico parece haber sido cuidadosamente evaluado y escogido.

Como leemos en la presentación de los editores del primer libro, es posible diferenciar tres períodos en la carrera científica y médica de Lutz. Entre 1881 y 1892 el trabajo de Lutz está dedicado a los estudios clínicos y al estudio de especies relacionadas con patologías humanas. Durante el segundo período, entre los años 1893 y 1908, estará al frente del Instituto Bacteriológico del Estado de São Paulo. Es en ese momento que se institucionalizan en Brasil tanto la medicina bacteriológica heredera de los enseñamientos de Pasteur como la medicina tropical. Por fin, en 1908 ingresa al Instituto Oswaldo Cruz dedicándose plenamente a la investigación, aun a aquella sin aplicación médica inmediata.

Pero, en los tres períodos podemos adivinar una preocupación recurrente por las enfermedades tropicales, desde los estudios de fiebre amarilla y malaria silvestre hasta su trabajo sobre dermatología y micología, incluyendo sus hipótesis de transmisión vectorial de la lepra. Existe una preocupación que se reitera, la de definir el modo de transmisión específico de las enfermedades parasitarias o de aquellas que exigen la intermediación de vectores para su propagación.

La edición de las Obras Completas de Lutz representa, para todos aquellos interesados en el estudio de la historia de la medicina en general y de la medicina tropical en particular, una fuente de valor inestimable para comprender la especificidad de esa área de estudios tantas veces confundida con un capítulo más o con una simple extensión de los estudios microbiológicos de esas enfermedades que aparecían inesperadamente en las regiones tropicales, muchas de las cuales eran territorios coloniales. 
Los estudios realizados por Lutz en diversas áreas tales como protozoología, parasitología, clínica, leprología, helmintología o zoología médica, nos permiten analizar de una perspectiva privilegiada las relaciones existentes entre los estudios provenientes de la microbiología y ese nuevo espacio de saber que surge a fines del siglo XIX e inicios del siglo XX, la medicina tropical. En ese momento es posible observar dos estrategias explicativas, dos modelos de inteligibilidad de las enfermedades que conviven: por un lado la investigación pasteuriana de los agentes microbiológicos de las enfermedades y la búsqueda de sueros y vacunas específicas para cada enfermedad; por otro, los estudios de la medicina tropical interesados en desvendar las interacciones entre los seres vivos, en comprender las cadenas de transmisión que envuelven los huéspedes intermediarios donde parásitos y microorganismos realizan parte de su ciclo vital y que sirven como vectores para la propagación de enfermedades.

Si para comprender la especificidad de la medicina tropical resulta necesario observar el papel desempeñado por los naturalistas, zoólogos y entomólogos, sin duda podremos encontrar en las investigaciones de Lutz sobre helmintología y entomología médica un espacio privilegiado de análisis.

Lutz puede ser reconocido, fundamentalmente, como un médiconaturalista y es esa mirada la que encontramos en sus investigaciones sobre microcrustáceos, en su estudio sobre la malaria silvestre y en sus trabajos sobre leprología. Quizás esa mirada de naturalista, en total sintonía con las teorías darwinianas, nos permita entender una extraña coincidencia. En el año 1897, Lutz descubre en el interior de las bromeliáceas el vector de la malaria silvestre (denominado Anopheles lutzii por Theobald, hoy reconocido como Kerteszia cruzii); en ese mismo momento, Ross se lamentaba por la precariedad de su trabajo como entomólogo amateur y por las dificultades encontradas para clasificar las especies de mosquitos entre los que identificará el vector de la malaria aviaria.

Es esa misma mirada de naturalista la que Lutz privilegió por sobre las explicaciones climáticas y aclimatacionistas que clásicamente caracterizaron a los médicos militares europeos encargados de estudiar las patologías más recurrentes en las regiones tropicales. Así, como afirma Benchimol en la presentación del tercer libro, "embora as relações entre clima, raças e doenças fosse o tema que lhe parecia mais atraente aos europeus ... Lutz voltou-se sobretudo para os parasitos que causavam males a sua heterogênea clientela, e para os animales com os quais ela convivia".

Citemos a Lutz:

Ao considerar os efeitos crônicos do calor, permitir-me-ei uma pequena digressão pelo capítulo da aclimatação, um terreno em que tem medrado palavras vãs e pontos de vista puramente especulativos em lugar de conceitos precisos e de observações rigorosas. A expressão clima deve ser limitada ao conjunto dos fatores meteorológicos; por sua vez, a fauna e a flora de agentes patogê-nicos deveriam constituir o genuis loci endemicus et epidemicus (índole endêmica e epidêmica do lugar) ... Todos esses fatores têm de ser levados em 
consideração não havendo erro maior do que o de imputar meramente ao clima o fato de uma colônia comercial ou agrícola não medrar além da segunda ou terceira geração. (Lutz, 1891)

En ese mismo momento gran parte de los estudios de geografía médica publicados en los Anales de Medicina Naval y Colonial defendían explicaciones exclusivamente climáticas y raciales para las dificultades encontradas para establecer colonos europeos blancos en las colonias de clima tropical.

Siete años mas tarde, en 1898, fecha de publicación de Tropical Disease, Patrick Manson defenderá una posición idéntica a la de Adolpho Lutz. Manson, también heredero de la tradición darwiniana, estará más atento a las relaciones entre los seres, parásitos y predadores, que a las explicaciones climáticas. Para él, "cuanto más aprendemos de estas enfermedades, el rol de la temperatura per se deviene menos importante en la determinación de su distribución geográfica y cobra mayor importancia la fauna tropical" (Manson, 1898, p. xv)

Por fin, y para concluir esta extensa reseña, es preciso señalar que también es esa mirada de naturalista, siempre aliada a intereses médicos y clínicos, la que reaparece en los estudios que Lutz dedica a la lepra. Su hipótesis de transmisión vectorial de la lepra que lo acompañará hasta su muerte, en 1940, puede ser perfectamente comprendida dentro de la lógica explicativa que le posibilitó la comprensión de otras enfermedades asociadas a los trópicos. Descartadas las explicaciones hereditarias, descartadas las explicaciones climáticas, y ante la imposibilidad de obtener culturas puras del bacilo de Hansen o de inocularlo en un animal para reproducir la enfermedad, Lutz, tal como Manson lo había hecho en relación al beriberi, apostó una vez más en la eficacia que los estudios entomológicos habían demostrado. Para Manson el modelo parásito-vector parecía poder dar respuesta a enfermedades tan diferentes como el cólera o el beriberi. Del mismo modo, Lutz persistió en la idea de definir la lepra según el modelo de la malaria. Persistió en su mirada de médico naturalista que aliada a un amplio conocimiento clínico de las características de la enfermedad (evolución lenta, localización imprecisa) adquirido durante los años en que se desempeñó como leprólogo en Hawai, le permitieron mantener una firme oposición al aislamiento de los leprosos, medida que consideraba "deshumana, poco eficaz e incoherente". (Lutz, 1887).

Resta aguardar los volúmenes por venir y agradecer a los editores por permitirnos acceder a este valioso material.

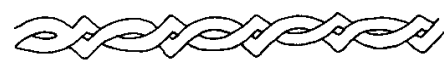

